\title{
John Banville: narrativa ecfrástica e picturalidade
}

\author{
John Banville: Ekphrastic Narrative and Pictoriality
}

Solange Viaro Padilha*

\section{RESUMO}

\begin{abstract}
A literatura e as artes visuais sempre estabeleceram um diálogo. Na Grécia antiga, poetas e filósofos já discutiam a proximidade entre a poesia e a pintura; a écfrase era utilizada como procedimento retórico. Na contemporaneidade, os entrelaçamentos intermidiais configuram um fértil campo de estudos comparatistas. Esta pesquisa investiga as relações entre a palavra e a imagem no romance $O$ livro das provas (1989), do autor irlandês John Banville, texto com o qual conquistou o Guinness Peat Aviation Award. Em tom confessional, o protagonista do romance rememora o passado utilizando uma narrativa não-linear, condizente com o tom memorialístico adotado. Suas referências à pintura acentuam o caráter pictural do texto, que discute a relação entre a vida e a arte e também a permeabilidade das fronteiras entre a realidade e a representação. Com base em estudos a respeito da écfrase, esta pesquisa pretende analisar a arquitetura textual de John Banville e destacar os marcadores picturais presentes no romance.
\end{abstract}

Palavras-chave: Écfrase; John Banville; Marcadores picturais.

* Faculdades Integradas Santa Cruz de Curitiba (FARESC). 
Padilha, S. V.

John Banville:

narrativa

ecfrástica e

picturalidade

Literature and the visual arts have always engaged in dialogue. In Ancient Greece, poets and philosophers already discussed the closeness between poetry and painting; ekphrasis was used as a rhetorical strategy. Nowadays, the intermedial studies embody a productive field of comparative studies. This article investigates the relations between word and image in the novel The Book of Evidence (1989), by Irish writer John Banville. The book won the Guinness Peat Aviation Award. In a confessional tone, the protagonist recollects his past and uses a non-linear narrative, compatible with the memorialistic nature of the novel. His mentioning of paintings reinforces the pictorial character of the text, which discusses the relation between life and art, as well as the permeability of the borders between reality and representation. Based on studies concerning ekphrasis, this article intends to analyze John Banville's textual architecture and to point out the pictorial markers within the novel.

Keywords: Ekphrasis; John Banville; Pictorial markers. 
Ele não conhece coisas maiores do que essas; mas é certamente tão valioso quanto o Paraíso de Dante, os Michelângelos e os Rafaéis e até mesmo os gregos. É tão belo quanto Zola, mais saudável e mais alegre, mas igualmente fiel à vida. (Carta de Vincent Van Gogh a Émile Bernard) autor irlandês John Banville é conhecido por sua prosa fluida, elegante. Sua obra prolífica abrange contos, romances, textos de não-ficção, um livro de memórias e ainda uma série de romances policiais, estes escritos sob o pseudônimo de Benjamin Black. Seu texto, metafórico e de uma complexidade ímpar, é pleno de referências intertextuais e interartísticas. Em seu processo compositivo, entre outros recursos, o autor emprega elementos comuns às artes visuais, especialmente aqueles relativos à pintura e à fotografia. O objetivo deste artigo é ressaltar a aproximação com as artes plásticas existente na narrativa de Banville, nomeadamente com a pintura. O percurso de investigação que se propõe está diretamente ligado à arquitetura textual desenvolvida pelo autor. Para tanto, apoiaremos o presente estudo em aspectos teóricos relativos à écfrase e aos marcadores de picturalidade.

Inúmeros são os textos que se propõem a investigar a origem e os usos da palavra écfrase. Segundo Ruth Webb (2009, p. 14), “Os Progymnasmata que oferecem as definições de écfrase como 'um discurso oral que traz o assunto vividamente diante dos olhos' pertencem aos primeiros séculos da Era Cristã”. Na definição que consta do conhecido The Classical Oxford Dictionary (2012, p. 495), a écfrase é "uma descrição literária extensa e detalhada de qualquer objeto, real ou imaginário". 
PAdilHa, S. V. John Banville: narrativa ecfrástica e picturalidade

Tradicionalmente, portanto, a écfrase pode ser vista como uma descrição pictórica ou literária de uma obra real ou imaginária. Claus Clüver (2017, p. 4) defende a ideia de que "Écfrase é a representação verbal de configurações reais ou fictícias compostas em uma mídia visual não-cinética", descartando as interpretações do termo que abrangem as mídias cinéticas, tais como o cinema e o vídeo.

João Adolfo Hansen $(2006$, p.3) traça o percurso histórico do uso da palavra e afirma que "Hoje, em tempos de desistoricização, o termo ekphrasis é usado para significar qualquer efeito visual." Não vamos ao ponto de considerar qualquer efeito visual na obra de Banville como écfrase, mas estenderemos o uso da palavra para a compreensão dos efeitos de descrição pictural no romance O livro das provas.

Lançaremos mão da teoria desenvolvida por Liliane Louvel no ensaio intitulado "A descrição "pictural": por uma poética do iconotexto". Destacaremos os elementos relativos à descrição pictural que, segundo Viola Winner (apud LOUVEL, 2006, p. 197), é a "técnica que permite descrever as personagens, os lugares, as cenas, ou os detalhes das cenas, como se eles fossem quadros ou conteúdos de quadros, e que [permite] a utilização de obras de arte com fins temáticos e estéticos”. Tal técnica descritiva, portanto, assinala um diálogo entre a literatura e as artes visuais.

\section{Modulações picturais}

No artigo supracitado, Liliane Louvel (2006) discute o conceito de iconotexto, enfatizando o entrelaçamento de dois códigos distintos: a palavra e a imagem. A autora elenca os marcadores de picturalidade considerados essenciais. Tais recursos, que podem apresentar-se de múltiplas maneiras, conferem ao texto uma inegável dimensão visual. A listagem seguinte, baseada nos textos de Louvel (2006; 2011), reúne os principais marcadores de picturalidade. São eles:

a) o uso de comparações explícitas "como se numa pintura";

b) os efeitos de enquadramento (a presença de janelas, portas e outros tipos de aberturas; narrativas de encaixe);

c) a presença de um personagem pintor ou esteta;

d) a descrição de uma obra de arte;

e) a focalização (a presença de um personagem em posição de voyeur; seu olhar guiará o leitor, constituindo a imagem como objeto de análise);

f) a suspensão do tempo como aquela indicada pelo gerúndio "-ndo", que também marca a inserção de uma subjetividade e, portanto, inscreve a espacialidade no tempo da narrativa;

g) o léxico especializado (cores, nuances, perspectiva, simetria e dissimetria, formas, massas, camadas, linhas, tintas, óleo, cavalete, efeitos de claroescuro, etc.);

Revista Letras, Curitiba, UFPR, n. 97 , pp. 130-142, 
h) a referência a gêneros picturais (natureza morta, retrato, marinha, paisagem) e a escolas de pintura;

Louvel (2011) propõe ainda a classificação de graus de saturação pictural, que variam da menor para a maior concentração de elementos que remetem ao pictural. O maior grau de saturação ela denomina écfrase, instância na qual necessariamente haverá a indicação de uma obra pictural. No entanto, devido à extensão e abrangência da teoria por ela desenvolvida, vamos nos ater aos marcadores picturais, cuja presença poderá ser detectada no texto ora analisado.

\section{O livro das provas e picturalidade}

Na obra banvilleana, o uso da luz ou o contraste luz e sombra, a presença de personagens que têm a pintura ou a fotografia como hobby ou profissão, a menção ao ato de registrar imagens por meio de tintas, esboços ou uma câmera, o vocabulário pertinente ao campo imagético e a descrição de telas ou fotografias propriamente ditas são marcas que revelam tanto o percurso do olhar como também um modo de percepção da realidade e da representação.

O livro das provas, romance com o qual John Banville obteve o Guinness Peat Aviation Award em 1989', é um exemplo de sua prosa vibrante. Na prisão, Frederick Montgomery, o narrador protagonista, escreve um texto confessional no qual relata os detalhes que o levaram ao cruel assassinato da testemunha do roubo

134 que ele perpetrara de uma tela do século XVII. Sua personalidade fragmentada e fantasiosa revela-se nessa confissão "em que fatos e ficção se misturam, construindo e desconstruindo sem fim a sua própria identidade” (MEDEIROS, 2002). Confissão, memória e fantasia tornam-se indissociáveis. Gradualmente, o leitor é conduzido por Freddie ao obscuro labirinto de suas memórias.

Sua afinidade e conhecimento das artes plásticas revelam-se por meio do forte apelo visual das imagens e metáforas que constrói ao longo da narrativa. Concordamos com Joseph McMinn quando assevera que

A significância literária de todo esse detalhe reside, talvez, naquilo
que ele nos diz a respeito das expectativas do autor em relação
ao leitor. Banville apoia-se profundamente nessas referências e
alusões para dar à sua narrativa certa erudição, uma qualidade
que reflete um conhecimento artístico por parte do narrador.
(McMINN, 209, p. 145-146)

Freddie encarna esse narrador, cujo conhecimento das artes revela-se a cada página. Em seu discurso, as imagens "não são apenas descrições, são também media da

1 The Book of Evidence foi publicado em 1989. A tradução para o português, intitulada O livro das provas, data de 2002 . 
Padilha, S. V.

John Banville:

narrativa

ecfrástica e

picturalidade

recordação" (ASSMANN, 2011, p. 190). Narrador-protagonista, faz referências explícitas a obras de pintores consagrados; discorre sobre gêneros picturais, tais como o autorretrato, o tema marítimo, a paisagem, a natureza-morta ou o retrato - itens que compõem a lista dos marcadores picturais elencados por Louvel -; emprega um rico vocabulário que remete à arte pictórica, ressaltando o caráter visual do texto.

Em uma de suas viagens, Freddie se questiona: "Como se pode pensar em perigo e crueldade num lugar tão paradisíaco, tão suave e azul, com paisagens de aquarela?" (BANVILLE, 2002, p. 17). Menções a diferentes gêneros de pintura acontecem ao longo do texto. Em outra passagem, descreve o estúdio do pintor que faz o retrato de sua amiga Anna Behrens e a reação desta ao ser pintada: "Ela retrai-se como que subitamente apanhada em um possante foco de luz. Ninguém jamais a olhara daquela maneira antes" (BANVILLE, 2002, p. 128). O artista é colocado como alguém que enxerga além das aparências, que enxerga aquilo que a própria Anna não via em si. A jovem "Continua a olhar para o retrato. Esperava que fosse como se ver em um espelho, mas tem diante de si alguém que não reconhece e que, entretanto, conhece profundamente" (BANVILLE, 2002, p. 130). Há um momento de instabilidade nesse reconhecimento de si mesma mediado pelo olhar do outro; levanta-se o questionamento entre realidade e representação. Por que motivo a moça não vê a tela como um espelho, e, embora não se reconheça, ainda assim tem a sensação de que conhece profundamente o ser representado, como se fosse um outro "eu" que a observa? Questões relativas à identidade são inerentes ao texto.

Além da menção a gêneros picturais, é manifesta a presença de outros marcadores, tais como a presença de personagens ligados às artes. Frederick Montgomery afirma que seu pai fora aficionado:

Impressiona-me, por exemplo, a frequência com que as pinturas aparecem neste caso. Foi através da arte que meus pais conheceram Helmut Behrens - bem, não foi exatamente através da arte, mas da coleção de arte. Meu pai gostava de se crer um colecionador de arte. Eu já não havia mencionado isso antes? É claro que ele não se importava nem um pouco com as obras em si, mas com o que representavam em dinheiro sonante. Aproveitava-se de sua fama [...] para insinuar-se junto aos velhos decrépitos que conhecia e em cujas casas havia visto, uns trinta e quatro anos antes, uma paisagem, uma natureza-morta ou um retrato muito antigo de um ancestral vesgo que àquela altura deveria valer alguns poucos trocados. (BANVILLE, 2002, p. 76)

Nesse trecho, é clara a referência a um personagem que, embora não fosse um pintor ou esteta, era um colecionador de arte.

Ao aludir à esposa, Daphne, Freddie descreve suas linhas, volume e proporção:

Revista Letras, Curitiba, UFPR, n. 97 , pp. 130-142, jan./jun. 2018. ISSN 2236-0999 (versão eletrônica)
Ela é uma mulherona. Não que seja gorda ou pesada, mas é massuda e bem proporcional. Sempre que a via nua tinha desejo de 
acariciá-la como se acaricia uma mulher esculpida, preenchendo com as curvas o côncavo da mão, passando o polegar lentamente pelas linhas firmes e lisas, sentindo-lhes o frescor, a textura aveludada da pedra. (BANVILLE, 2002, p. 13-14)

Sua escolha vocabular recai no léxico especializado: ele descreve proporções, linhas, texturas e compara Daphne a uma escultura feita em pedra. Fala ainda de quando saía com ela e de como era bom "caminhar sem pressa até o embarcadouro, atravessando a rígida geometria de sol e sombra nas ruas estreitas" (BANVILLE, 2002, p. 15). Luz e sombra se misturam, tanto na paisagem quanto no interior do personagem.

Freddie expressa seu carinho pela esposa. Algumas de suas memórias parecem emolduradas como quadros:

Lembro-me de uma cena passada há muitos anos, não tenho a menor idéia do lugar. Era um fim de festa e encontrei-a de pé junto a uma janela. Usava um vestido branco e estava totalmente absorta naquela tênue luz de um amanhecer de abril. [...] Eu poderia ter ficado ali, num canto escuro, a observá-la. Poderia ter gravado aquela imagem ternamente nas paredes nuas do meu coração e ela ainda estaria lá, vívida como naquela madrugada, minha triste e misteriosa amada. (BANVILLE, 2002, p. 88)

De maneira confessional, o protagonista do romance rememora o passado utilizando uma narrativa não-linear, condizente com o tom memorialístico adotado. A sutileza do tecido poético surge de seus recortes e escolhas lexicais.

Naturalmente, sabemos que o que Freddie revela pode não ser a expressão daquilo que realmente se passou; ele mesmo se questiona quanto à natureza de suas memórias, admitindo que elas podem estar adulteradas por diversos filtros de ordem mental, emocional, temporal. Na perspectiva de Webb,

[...] a visualização da cena que o falante deseja colocar diante dos olhos da audiência baseia-se em elementos que já residem em sua memória e, a menos que seja uma cena que ele já tenha testemunhado, é um composto de imagens existentes. $\mathrm{O}$ fato de que as imagens da memória não permanecem inertes, mas estão sujeitas à manipulação, significa que a phantasia ou phantasmata não devem ser tidas como limitadas à reprodução quase-fotográfica das coisas vistas. Por vários processos, as imagens que advêm da experiência podem formar nova matéria prima para novas composições. (WEBB, 2009, p. 119)

Nesse sentido, as imagens formadas na mente de Freddie Montgomery, e que por vezes ele afirma estarem distorcidas, são a expressão de imagens mentais formuladas a partir de um arcabouço particular, uma espécie de arquivo onde 
PAdilha, S. V. John Banville: narrativa ecfrástica e picturalidade

estão gravadas cenas - vividas e/ou fantasiadas - que se tornaram seu banco de dados particular. É a esse arquivo particular que ele recorre para interpretar os fatos e fazer analogias com as cenas vividas, a partir da sua experiência e do seu conhecimento de mundo.

Somente aos poucos esse personagem descortina sua história, expõe facetas de sua vida. Afinal, quem é Freddie Montgomery? A que se dedica? Progressivamente, sua paixão se revela: "Estudei os métodos de triturar os pigmentos, o comércio de óleos e solventes, a manufatura de telas em Flandres. Li sobre a vida dos pintores e de seus benfeitores. Tornei-me um pequeno expert na Holanda do século dezessete (BANVILLE, 2002, p. 247-248). Curiosamente, Freddie dedica-se a estudar o período ao qual a tela roubada - Retrato de uma mulher com luvas - pertence: "Presume-se que haja sido pintado entre 1655 e 1660. No vestido negro com a grande gola branca e os punhos sobressaem apenas o broche e os enfeites de ouro das luvas. O rosto tem um leve toque da Europa Ocidental” (BANVILLE, 2002, p. 125). Percebemos que, além de haver uma menção ao título da tela, ela é efetivamente descrita.

Para Louvel (2006, p. 217), a citação de uma obra de arte - real ou fictícia aponta para uma riqueza interdisciplinar, "de referências à tradição, de glosas, de comentários, de interpretações, de avaliações, de julgamentos estéticos”. A plena saturação pictural (ekphrasis, na acepção de Louvel) levará a uma "abertura do texto às artes visuais e a uma estética heterogênea” (p. 217), o que demandará um leitor com competência tanto no âmbito da leitura das palavras quanto das imagens.

Tamar Yacobi (1995, p. 600) assegura: “[...] ekphrasis, a evocação literária da arte espacial, é um termo guarda-chuva que admite várias formas de reproduzir o objeto visual em palavras". Um termo guarda-chuva, por sua natureza, compreende diversas acepções. Na concepção de Melina Rodolpho:

A écfrase/descrição consiste no processo descritivo detalhado por meio do qual se pode produzir um 'quadro' do objeto da descrição; temos então a enargia/evidência, que pode ser considerada figura de pensamento cuja finalidade é conferir vivacidade à imagem verbal. A écfrase não é o único procedimento capaz de gerar essa enargia, conforme se verá; contudo, nos desperta o interesse em razão de sua história, pois é frequentemente associada à construção de imagens que, por sua vez, representam objetos inexistentes de maneira absolutamente crível. (RODOLPHO, 2010, p. 8)

Freddie descreve algumas cenas com tal vivacidade que seguramente poderiam ser transpostas em um quadro, realizando aquilo que Louvel (2006, p. 196) identifica como "translação intermidiática". Ele parece pintar com palavras; sua habilidade linguística e sua capacidade de evocar imagens conferem ao texto uma dimensão pictural ímpar.

Depois de assassinar Josie Bell, a jovem que o flagrara roubando o quadro do século XVII, ele perambula sem rumo e sem saber exatamente onde se encontra:

Revista Letras,

Curitiba, UFPR, n. 97 , pp. 130-142, jan./jun. 2018. ISSN 2236-0999 (versão eletrônica) 
De um lado da estrada erguia-se uma colina abruptamente; do outro, via-se, para além dos topos dos pinheiros, o rio descendo em corredeiras. Toda aquela visão parecia absurda. Era como se houvessem pintado às pressas um cenário improvável, com o horizonte a perder de vista e aquela estradinha inocente a dar voltas até desaparecer no infinito. (BANVILLE, 2002, p. 136)

Mesmo num momento de tamanha tensão, sua sensibilidade para o aspecto pictural da natureza se deixa entrever por meio de suas palavras. A comparação com a pintura é notória: "como se houvessem pintado um cenário improvável". E a menção a aspectos dessa vista pitoresca, tais como colina, rio, corredeiras, horizonte e estradinha sinuosa, enfatiza a qualidade pictural da descrição.

Freddie Montgomery enxerga a paisagem e muitas cenas do cotidiano 'como se fossem' telas. Seu reencontro com Anna Behrens, amiga da juventude, é descrito da seguinte forma:

Vi-a, por acaso, em uma galeria na Shattuck Avenue. [...] Fiquei parado algum tempo na rua observando-a - admirando-a, certamente. A galeria era um enorme salão envidraçado e ela estava encostada em uma mesa com uns papéis na mão, lendo. Usava um vestido branco. Seus cabelos, prateados pelo sol, estavam penteados de maneira elaborada, com uma única trança grossa descendo-lhe pelo ombro. Absolutamente imóvel e iluminada pelo sol que atravessava o vidro, ela parecia uma das obras de arte da exposição. (BANVILLE, 2002, p. 77)

Nesse pequeno trecho, observam-se marcadores picturais diversos. Temos um efeito de enquadramento da moça que é vista através da vidraça que a emoldura. Do lado de fora, Freddie é o voyeur que, sem ser visto, secretamente admira a jovem como se ela fosse uma obra de arte exposta na galeria. Suas palavras induzem o leitor a mirá-la mais atentamente e a compartilhar o prazer desse momento voyeurístico, instante em que a luz do sol não somente ilumina o tema central da tela, mas é parte integrante de toda a composição.

Enfatizando o emprego de marcadores picturais, temos ainda a menção a nomes consagrados das artes visuais no Ocidente, tais como Rembrandt, Franz Hals, Vermeer, Tintoretto, Fragonard, Watteau, Klimt, El Greco, entre outros. Todos os nomes são citados em contextos específicos. A título de exemplo, ao relatar uma viagem que fizera na companhia de Daphne, Freddie assegura: "Lembro-me de um quarto com persianas verdes, uma cama estreita e uma cadeira como a de Van Gogh. O sol a pino do Mediterrâneo pulsava lá fora e reverberava nas ruas brancas. Ibiza? Ischia? Mykonos, talvez? Era sempre uma ilha" (BANVILLE, p. 2001, p. 13). Ao mesmo tempo em que a descrição ecfrástica assinala o conhecimento do narrador em relação às artes, a comparação com o quarto de Van Gogh dá indícios ao leitor de que o ambiente em que o personagem se encontrava não era luxuoso, que a cadeira era rústica, que suas finanças não lhe permitiam circular 
Padilha, S. V. John Banville: narrativa ecfrástica e picturalidade

por hotéis requintados. Portanto, há uma camada sutil de informação a respeito do personagem que é veiculada por meio das analogias com obras de arte.

O pintor holandês é mencionado novamente, na ocasião em que Freddie sai à procura do amigo Randolph:

Encontrei-o com um grande curativo no lado esquerdo da cabeça. A bandagem fora feita de qualquer maneira e não parecia limpa. Ele já não tinha mais o jeito de caubói de filme do faroeste. Como estava, parecia que o destino resolvera fazer dele um Van Gogh o do auto-retrato depois de cortar a orelha. Quando me viu, deu a impressão de que ia chorar. (BANVILLE, 2002, p. 21)

Randolph mostrava-se fragilizado, amedrontado, em vias de perder o controle sobre si mesmo. A comparação com o autorretrato de Van Gogh, portanto, cumpre uma dupla função: além de ser um investimento na carga de picturalidade do texto, ainda sugere ao leitor toda uma gama de interpretações possíveis.

Pode-se dizer que o romance banvilleano desafia a bagagem cultural e o potencial do leitor. Aquele que

reconhecer a alusão a um estilo de pintura ou a uma obra de arte notável, apreciará um padrão de significado bastante distintivo e sugestivo em um texto, algo que praticamente se perderá num leitor que não tenha esse tipo de conhecimento ou experiência. O leitor de Banville deve ser culto ou curioso, preferencialmente ambos. (McMINN, 2006, p. 146)

O texto de Banville propõe um jogo ao leitor, que deverá acessar todo o seu conhecimento para melhor compreender as referências culturais, intertextualidades e alusões propostas pelos personagens.

Nointuito de dar continuidadeà análise dos marcadores visuais, verificaremos outros mecanismos utilizados na narrativa. Observemos um trecho da cena inicial do romance:

A manhã raiou desbotada em Madri. Fiquei parado ao sair da estação, observando uma revoada de pássaros que davam voltas e se lançavam de grande altura. Foi aí que senti uma coisa muito estranha, uma espécie de euforia que se apossou de mim, fazendo-me tremer e enchendo meus olhos de lágrimas. (BANVILLE, 2002, p. 31)

Entre os indicadores do caráter visual do texto, destacam-se tempos e aspectos que transmitem o caráter de narrativização dos elementos picturais. Tais elementos indicam uma "suspensão da ação, uma dilatação do tempo", uma espécie de "imobilização, de neutralização temporal" (LOUVEL, 2006, p. 213) que alonga a narrativa, indicando a Curitiba, UFPR, n. 97 , pp. 130-142, jan./jun. 2018. ISSN 2236-0999 (versão eletrônica)
Revista Letras, 
lançavam) são intensificados pela presença de formas no gerúndio (observando, fazendo, enchendo) que, de maneira sutil, sugerem a suspensão do tempo.

Freddie descreve mais uma viagem: "De onde eu estava sentado, à frente, a proa dava a impressão de erguer-se cada vez mais, como se o barco estivesse se esforçando para alçar vôo. [...] Ergui o rosto para aquela calma luz do mar, extasiado" (BANVILLE, 2002, p. 35). Louvel (2006, p. 213) assegura que a narrativização também se dá por meio do emprego de "particípios passados com valor de adjetivo, resultados de uma ação passada". $\mathrm{Na}$ passagem em destaque, a presença das palavras sentado e extasiado - particípios passados (com valor de adjetivo) - ressalta o caráter de descritivo do texto.

$\mathrm{O}$ relato de Freddie Montgomery, como sói acontecer com os relatos memorialísticos, é impreciso, carregado de lacunas e de meandros obscuros. Ao mesmo tempo em que o personagem tenta voluntariamente resgatar suas memórias, muitas vezes percebe que o conteúdo resgatado não é necessariamente idêntico aos fatos anteriormente vividos. De qualquer maneira, preso e afastado de seu círculo social, escreve, talvez por perceber que "a escrita é uma das armas mais eficientes contra a segunda morte social, o esquecimento” (ASSMANN, 2011, p. 195). Enjaulado, Gilles o Terrível, como por vezes se autodenominava, espera o julgamento. Ao elaborar sua própria defesa, Freddie solicita ao inspetor que seu texto seja anexado ao processo, junto às "outras peças de ficção - as oficiais" (BANVILLE, 2002, p. 253), induzindo-nos uma vez mais a questionar a dicotomia arte versus representação. O Inspetor Haslet demonstra incredulidade: "Ora, Freddie, o que há de real nessa história?” A resposta é paradoxal: “O que há de real, inspetor? Tudo é real. Não, nada é real. Apenas o desespero é real” (p. 253).

Ao leitor resta indagar qual é a natureza e qual é a raiz desse desespero. A resposta, assim como a vida, assim como a narrativa de Montgomery e também a de Banville, é multifacetada. O que é real? Freddie dispara:

Nada disso significa coisa alguma. Isto é, nada que tenha qualquer importância. Estou apenas me distraindo, divagando, perdendo-me em um montão de palavras. Pois as palavras aqui são uma espécie de luxo, de exuberância. De tudo mais que tínhamos nesse mundo de riquezas e desperdícios que deixamos lá fora, as palavras são só o que nos deixam continuar a ter. (BANVILLE, 2002, p. 49)

Resta-nos o luxo das palavras de John Banville e a inquietação provocada pelas palavras de Freddie Montgomery.

\section{Considerações finais}

As evocações poéticas do texto de Banville são como estruturas ou escrituras palimpsésticas, uma vez que trazem ecos de diversos textos e mídias distintas. Por meio da palavra e da descrição ecfrástica, o autor convoca a presença das artes visuais, o que confere ao texto uma forte carga imagética. 
Padilha, S. V.

John Banville:

narrativa

ecfrástica e picturalidade

Em nossa leitura, pudemos observar que o romance O livro das provas encerra inúmeros marcadores de picturalidade, tais como a presença de um personagem esteta; o emprego do léxico especializado; o uso de comparações explícita; efeitos de enquadramento; a referência a gêneros picturais, a presença de um personagem em posição de voyeur; a suspensão do tempo; o uso de comparações explícitas; a descrição de obras de arte. Segundo Louvel (2006), tais marcadores configuram uma abertura do texto a uma estética híbrida, o que demanda um conhecimento tanto da estética literária quanto da poética das artes visuais.

Para Yacobi (1995), faz-se necessário investigar em que circunstâncias o diálogo interartístico se dá e quais os efeitos obtidos por meio dessa junção. Em Banville, o diálogo se dá por meio da modulação pictural e da analogia com as artes visuais. Nas palavras de McMinn (2006, p. 149), "Pode-se argumentar que o estilo poético de Banville, especialmente em sua afeição pela analogia intrincada e engenhosa, é ímpar na história do romance irlandês moderno e contemporâneo". Indubitavelmente, grande parte da potência do texto banvilleano reside uso de marcadores picturais, na intensidade e na densidade de suas metáforas e analogias com as artes visuais.

Pelo tom confessional e memorialístico de Freddie Montgomery, pela narrativa não-linear, pela escrita palimpséstica, labiríntica e multifacetada, pelas diversas camadas de sentido, O livro das provas configura-se como uma armadilha textual que clama por reatualizar o grande desafio: "Decifra-me ou eu te devoro". 


\section{Referências}

ASSMANN, Aleida. Espaços da recordação: formas e transformações da memória cultural. Tradução: Paulo Soethe. Campinas, SP: Editora da Unicamp, 2011.

BANVILLE, J. O livro das provas. Tradução Maria Alice Máximo. Rio de Janeiro: Record, 2002.

CLÜVER, Claus. A New Look at an Old Topic: Ekphrasis Revisited. Todas as Letras, São Paulo, v. 19, n. 1, p. 30-44, jan./abr. 2017.

HANSEN, João Adolfo. Categorias epidíticas da ekphrasis. Revista USP, São Paulo, n.71, p. 85-105, setembro/novembro 2006.

HORNBLOWER, Simon; SPAWFORTH, Antony (Ed.). 4th Edition. The Oxford Classical Dictionary. Oxford: OUP, 2012.

LOUVEL, L. A descrição "pictural": por uma poética do iconotexto. In ARBEX, Márcia (org.) Poéticas do visivel: ensaios sobre a escrita e a imagem. Belo Horizonte: Programa de Pós-Graduação em Letras: Estudos Literários, Faculdade de Letras da UFMG, 2006. p. 191-220.

Poetics of the Iconotext. Edited by Karen Jacobs and translated by Laurence Petit. Farnham: Ashgate, 2011.

MCMINN, Joseph. 'Ah, This Plethora of Metaphors! I Am like Everything Except Myself': The Art of Analogy in Banville's Fiction. Irish University Review, Vol. 34, 142 No. 1, Special Issue: John Banville (Spring - Summer, 206), pp. 134-150.

MEDEIROS, Sérgio. A consciência imponderável. Folha de São Paulo, São Paulo, 06 out. 2002. Disponível em: <http://www1.folha.uol.com.br/fsp/mais/ fs0610200214.htm>. Acesso em: 30 nov. 2017.

RODOLPHO, M. Écfrase e evidência nas Letras Latinas: doutrina e práxis. $213 f$. Dissertação - Programa de Pós-Graduação em Letras Clássicas do Departamento de Leras Clássicas e Vernáculas da Faculdade de Filosofia, Letras e Ciências Humanas da Universidade de São Paulo, 2010. Disponível em <http://www.teses. usp.br/teses/disponiveis/8/8143/tde-26042010-111303/pt-br.php >. Acesso em: 20 nov. 2017.

WEBB, Ruth. Ekphrasis, Imagination and Persuasion in Ancient Rhetorical Theory and Practice. Surrey, England: Ashgate, 2009.

YACOBI, Tamar. Pictorial Models and Narrative Ekphrasis. Poetics Today, Vo. 16, No. 4, (Winter, 1995), pp. 599-649.

Submetido em: 04/03/2018

Aceito em: 04/04/2018 